\title{
Histological and immunohistochemical study of the potential healing effects of glucosamine and platelets rich plasma on experimentally induced oral mucositis in adult male rats
}

Aisha E. Mansy, Nahla El-Eraky El-Azab and Abeer M. El-Mahalaway*

*Correspondence: abeerelmahalaway@yahoo.com

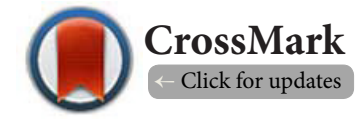

Departments of Histology and Cell Biology, Benha Faculty of Medicine, Benha University, Egypt.

\begin{abstract}
Background: Oral mucositis $(\mathrm{OM})$ is mucosal barrier injury. It is commonly caused by 5 Flurouracil (5-FU). Glucosamine (GlcN) has many beneficial therapeutic effects. Platelets rich plasma (PRP) are a promising line for curing ofvarious clinical injuries.

Objective: The aim of the study was to evaluate the effect of glucosamine and PRP on experimentally induced oral mucositis in adult male rats.

Materials and methods: 40 adult male rats divided evenly into four groups. Group I (Control). Group II (Mucositis): rats injected one time intraperitoneally with $5-\mathrm{FU}(150 \mathrm{mg} / \mathrm{kg}$ body weight).Group (III) (Mucositis treated with glucosamine): rats injected intraperitoneally with glucosamine $(1000 \mathrm{mg} / \mathrm{kg}$ body weight) following induction of oral mucositis for 3 weeks. Group IV (Mucositis treated with PRP) rats injected with $\mathrm{PRP}(1 \mathrm{ml} / \mathrm{rat} /$ day $)$ locally into buccal mucosa following induction of oral mucositis for 3 weeks. Buccal mucosa samples prepared and examined by using histological and immunohistochemical techniques.

Results: Group II showed apparent diminish in the thickness of the epithelium with separation of keratin, hemorrhage and perinuclear vacuolization. There were areas of degeneration, intense subepithelial mononuclear infiltration and cell apoptosis (highly expressed caspase-3). A significant reduction of Periodic acid Schiff (PAS) positive reaction and anti-proliferating cell nuclear antigen (PCNA) positive nuclei $(\mathrm{P}<0.01)$. Group III\&IV showed improvement of the histological and immunohistochemical changes described before.

Conclusion: Glucosamine and PRP provide a promising treatment for oral mucositis accompanying with chemotherapy. PRP remedy is simple and the most efficient mean as it exhibits more rapid epithelial differentiation and wound healing.
\end{abstract}

Keywords: Glucosamine, 5-FU, Mucositis, PRP, Caspase -3, PCNA

\section{Introduction}

Oral mucous membranes are specialized frail membranes. Oral mucositis (OM) is defined as mucosal barrier injury as result of destruction of its mucosal epithelium or inhibition of its growth leading to alteration of the function and integrity of the oral cavity. It may appear anywhere in the mouth, but are regularly found on the interior of the lower lip or cheeks,or on the sides or base of the tongue [1-3]. It can induce many complications, vary from speech and swallowing troubles to severe pain and ulcer over infection, which can advance into systemic infection (bacteremia or fungemia). Finally threating to patient lifestyle due to decrease their nutritional status with increased their economic burden and demanding to their hospitalization $[4,5]$.

Oral mucositis is induced as result from the most debilitating side effects of chemotherapy treatment, the most famous one is 5-Fluorouracil (5-FU), radiotherapy and various forms of trauma as mechanical, chemical or thermal agitation of the mucosa $[1,6]$.

The approaches for the therapy of oral mucositis established 
through several regimens such as local anesthetics, anti-ulcer and anti-inflammatory agents. Herbal remedy and laser therapies are also applied in its management. Despite recent advances, there are not any effective therapy for oral mucositis [7].

Glucosamines (GlcNs) tried as an alternative therapeutic regimen for oral mucositis. Glucosamine (2-amino-2-deoxyD-glucose) is an amino monosaccharide precursor of the disaccharide unit of glycosaminoglycans (GAG), the building block of proteoglycans. These proteoglycans form the matrix of the all connective tissues as cartilage. Glucosamine is a precursor and inducer factor for chondrocyte and connective tissue GAG synthesis. Moreover, it is a sugar synthetized in the body, besides it exists in minute amount in food. Glucosamine has different forms as sulphate or hydrochloride form, though glucosamine sulphate is the most ordinary and extensively used form [8]. Glucosamine possess extreme biological effects as membrane stabilization and hepatic preservation. It also augments the synthesis of hyaluronic acid and is applied for the curing of osteoarthritis and skin injuries $[9,10]$.

Recently PRP supply a promising alternate line for various medical applications as repair of chondral and tendon lesions, restoration of injuries and bone renewal besides curing of plantar fasciitis, severe diabetic foot ulcers and burns. PRP promotes bone, muscle, tendon, cartilage and skin growth and minimizes both pain and inflammation [11-13]. PRP is an autologous output of blood and it formed of a high platelet concentration in a small quantity of plasma. It has great advantage on clinical proposal as it is an cheap product, easy to obtain, and there is no risk of rejection or immune reaction and also had an antimicrobial action [12,14].

The present study conducted to evaluate the effect of glucosamine and PRP on experimentally induced oral mucositis in adult male rats.

\section{Material and methods}

40 adult male rats with a weight about $180-200$ grams were used in this research. Rats settled in the animal research laboratory unit of Kasr Al-Ainy Faculty of Medicine, Cairo University. Firm nursing and cleaning procedures employed to keep the animal in a typical well condition, the animals were settled in animal coop at room temperature $\left(25 \pm 1^{\circ} \mathrm{C}\right)$, the proportional humidity $(55 \pm 5)$ with $12 \mathrm{~h}$ light/ $12 \mathrm{~h}$ dark cycle, mash usual nutrition and water ad- libitum. Rats acclimated to these conditions for two weeks before beginning the experiment. All morals rules for animal management were monitored. The experimental procedure was as per the ethics regulation of the Institutional Animal Care Committee.

\section{Used drugs}

Glucosamine (GlcN) and 5-Fluorouracil (5-FU) purchased from Sigma -Aldrich Corp. (St. Louis, MO, USA).

\section{Induction of oral mucositis}

Oral mucositis induced by single intraperitoneal (i.p.) injection of 5 -fluorouracil (5-FU) $(150 \mathrm{mg} / \mathrm{kg}$ body weight). The rats sacrificed under mild anaesthesia after seven days of 5-FU injection $[15,16]$.

\section{Preparation of PRP}

The fresh blood sample obtained by puncture of rats' hearts with a tube containing sodium citrate. The accumulated blood was initially centrifuged at $160 \mathrm{~g}$ for 20 minutes at room temperature $\left(22^{\circ} \mathrm{C}\right)$. Then, a lower red cell component and an upper straw-yellow unclear serum component were observed. A point was marked at $1.4 \mathrm{~mm}$ below the line dividing the two fractions. The entire amount above this point pipetted and conveyed to another $5 \mathrm{ml}$ vacuum tube whereas line identical to $0.35 \mathrm{ml}$ towed from the tube's bottom. The sample transferred to a new centrifugation at $400 \mathrm{~g}$ for 15 minutes. Two constituents observed; the first was up and included platelet-poor plasma and the second was down the line drawn on the tube was PRP [17].

\section{Experimental design}

Rats divided equally into four groups10 animals each.

\section{Group I (Control)}

Rats of this group further subdivided equally into two subgroups.

Subgroup la: Each rat received $1 \mathrm{ml}$ saline once orally.

Subgroup Ib: Each rat injected only one time intraperitoneally with $1 \mathrm{ml}$ phosphate buffer saline (PBS) as the vehicle of 5 -FU and GlcN for three weeks.

Rats of each subgroup sacrificed together at same duration with the corresponding experimental groups.

\section{Group II (Mucositis)}

Rats injected once intraperitoneally with $5-\mathrm{FU}(150 \mathrm{mg} / \mathrm{kg}$ body weight) with PBS as the vehicle of 5-FU [10].

\section{Group III (Mucositis treated with glucosamine)}

Rats injected intraperitoneally with GlcN $(1000 \mathrm{mg} / \mathrm{kg}$ body weight) with PBS as the vehicle of GlcN daily for three weeks following oral mucositis induction by5-FU [18].

Group IV (Mucositis treated with platelets -rich plasma) Under local anesthesia with diethyl ether, rats injected with PRP ( $1 \mathrm{ml} / \mathrm{rat} /$ day) locally into erythematous changes of buccal mucosa for three weeks following oral mucositis induction by 5 -FU. Injection did by using $1 \mathrm{ml}$ insulin syringe with a needle size 27-gaugex $1 / 2$ inch [19].

Rats from groups III and IV sacrificed at the 28day from beginning of experiment, while the rats of group II sacrificed after seven days of 5-FU injection.

\section{Light microscopic studies}

Buccal samples fixed in 10\% formalin for 48 hours. Paraffin sections (5- $\mu \mathrm{m}$-thick) prepared, processed and stained with 
hematoxylin\&eosin (H\&E) and periodic acid-Schiff technique (PAS) [20]. Other sections placed on positively charged slides for immunohistochemical detection of caspase and antiproliferating cell nuclear antigen (PCNA) [21].

\section{Immunohistochemical studies}

1. Imunohistochemical staining for detecting of caspase-3 (index for apoptosis), the primary monoclonal antibody used was rabbit anticleaved caspase- 3 monoclonal antibody (Cell Signalling Technology, Boston, MA, USA). The cellular site of the reaction was brown color in the cytoplasm of cells lining the buccal mucosa.

2. Imunohistochemical staining for detecting of antiproliferating cell nuclear antigen (PCNA), the primary monoclonal antibody used was anti-PCNA IgG antibody (Sigma-Aldrich Inc.,U.K). The cellular site of the reaction was nuclear and brown color.

Imunohistochemical study conducted using the avidinbiotin peroxidase method, followed by diaminobenzidine (DAB) (Dakopatts, Glostrup, Denmark) added to slides as a chromogen, next the slides washed with distilled water. Later, the sections counter stained with hematoxylin. For the negative control, the specific primary antibody replaced by phosphatebuffered saline. The positive control for caspase -3 was a section from pancreas, while for PCNA was a section from skin.

\section{Morphometric analysis}

Using a Leica Qwin 500 image analysis computer system (Leica Microsystems Ltd, Cambridge, UK) at the Pathology department, Faculty of Medicine, Cairo University. Five slides from five unlike samples of each group examined and from each slide, ten non-overlapping fields measured.

The following measures assessed:

The mean area percentage of PAS positive reaction, positive immunoreactivity for caspase- 3 and PCNA at a magnification of $\times 400$. They calculated using the color detect menu and in relation to a standard measuring frame.

\section{Statistical analysis}

All the data collected from the experiment recorded and analyzed using IBM SPSS Statistics software for Windows, Version 20 (IBM Corp., Armonk, NY,USA). One-way analysis of variance (ANOVA) with Post Hoc Scheffe's test applied to compare differences among the groups. In each test, the data was evident as the mean (M) value \pm standard deviation (SD) and differences considered significant at $\mathrm{P}<0.01$.

\section{Results}

\section{Histological study \\ Haematoxylin\& eosin stain \\ Group I (Control)}

All the subgroups exhibited similar histological picture. The section of the control rats revealed normal histological architecture of the buccal mucosa. It composed of partially keratinized stratified squamous epithelium exhibiting rete ridges projecting into underlying lamina propria. The lamina propria formed of connective tissue (Figure 1a).

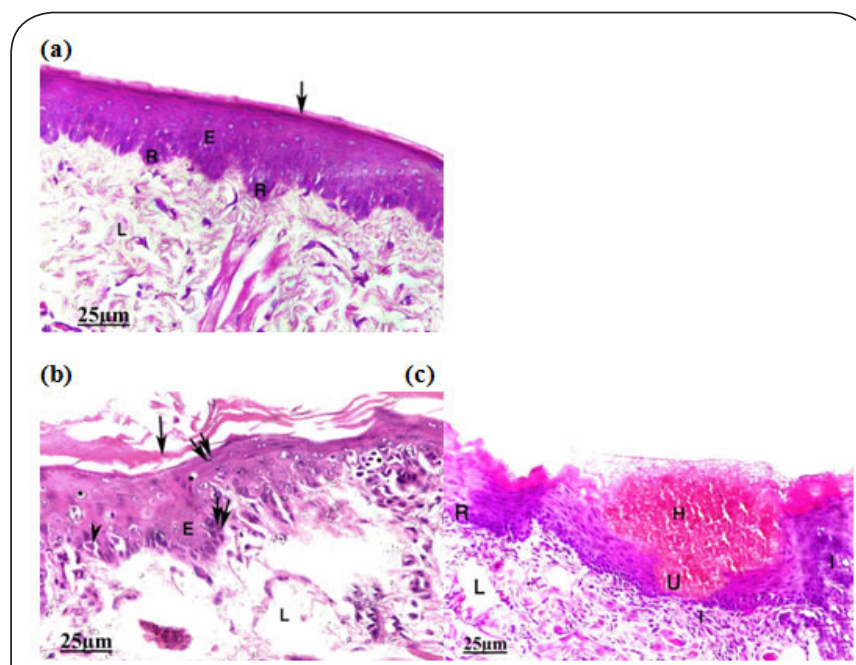

(d)

(e)

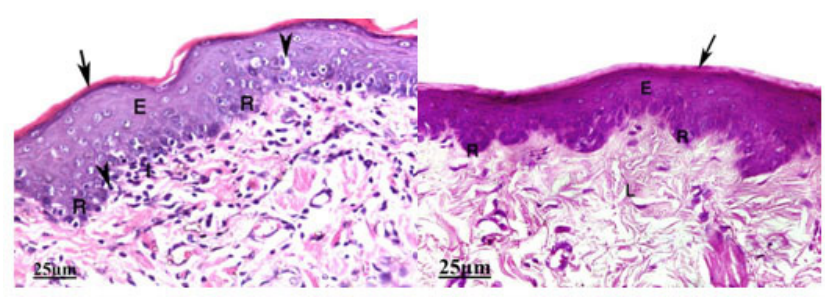

Figure 1. A photomicrograph of buccal mucosa stained with hematoxylin and eosin.

(a) Buccal mucosa section from group I showing the buccal mucosa with normal keratinized (arrow), stratified squamous epithelium (E) exhibiting rete ridges (R) and well organized lamina propria (L)[H\&E,X400,scale bar $=25 \mu \mathrm{m}]$. (b) Buccal mucosa from group II showing apparent decrease thickness of epithelium (E) with separation of keratin (arrow). Cytoplasmic perinuclear vacuolization of some epithelial cells ( $\boldsymbol{\Delta}$ arrow head), while others show deeply stained nuclei ( $\uparrow$ ) or fragmentation and loss of nuclei $\left.{ }^{*}\right)$. Areas of degeneration are seen in lamina propria $(\mathrm{L})[\mathrm{H} \& \mathrm{E}, \mathrm{X} 400$,scale bar $=25 \mu \mathrm{m}]$. (c) Buccal mucosa from group II showing hemorrhage $(\mathrm{H})$, focal erosion of squamous epithelium at ulcer area (U) and flattening of rete ridges (R). Notice intense mononuclear infiltration (I) and areas of degeneration (L) in lamina propria [H\&E, X400, scale bar $=25 \mu \mathrm{m}]$. (d) Buccal mucosa from group III showing keratin layer (arrow), apparently degree of re-epithelialization (E) and rete ridges $(\mathrm{R})$. Notice subepithelial mononuclear infiltration (I) and cytoplasmic perinuclear vacuolization ( $\boldsymbol{\Delta}$ arrow head) [H\&E, X400,scale bar $=25 \mu \mathrm{m}]$. (e) Buccal mucosa from group IV showing keratin layer (arrow), more or less normal stratified epithelium (E) and rete ridges (R) with well-organized lamina propria $(\mathrm{L})[\mathrm{H} \& \mathrm{E}, \mathrm{X} 400$,scale bar $=25 \mu \mathrm{m}]$.

\section{Group II (Mucositis)}

This group showed various histological changes in the form of apparent diminish in the thickness of the epithelium with separation of keratin. The cytoplasmic perinuclear vacuolization of some epithelial cells were seen. While others showed 
Mansy et al. Journal of Histology \& Histopathology 2017,

http://www.hoajonline.com/journals/pdf/2055-091X-4-12.pdf

deeply stained nuclei (pyknotic), fragmentation of nuclei (karyohexiss) or loss of nuclei (karyolysis). There were areas of degeneration in lamina propria (Figure 1b). Hemorrhage, focal erosion of squamous epithelium at ulcer area and flattening of rete ridges besides intense mononuclear infiltration and areas of degeneration were seen in lamina propria (Figure 1c).

\section{Group III (Mucositis treated with glucosamine)}

This group showed keratin layer and apparently degree of reepithelialization with restoration of rete ridges. Subepithelial mononuclear infiltration and cytoplasmic perinuclear vacuolization were seen (Figure 1d).

Group IV (Mucositis treated with platelet-rich plasma) This group revealed more or less normal stratified squamous epithelium, keratin layer and also rete ridges with wellorganized lamina propria (Figure 1e).

\section{PAS stain}

The control groups revealed intense PAS positive reaction in buccal mucosa (Figure 2a), but weak PAS positive reaction in group II (Figure $\mathbf{2 b}$ ), while intense PAS positive reaction in group III (Figure 2c) and group VI (Figure 2d).

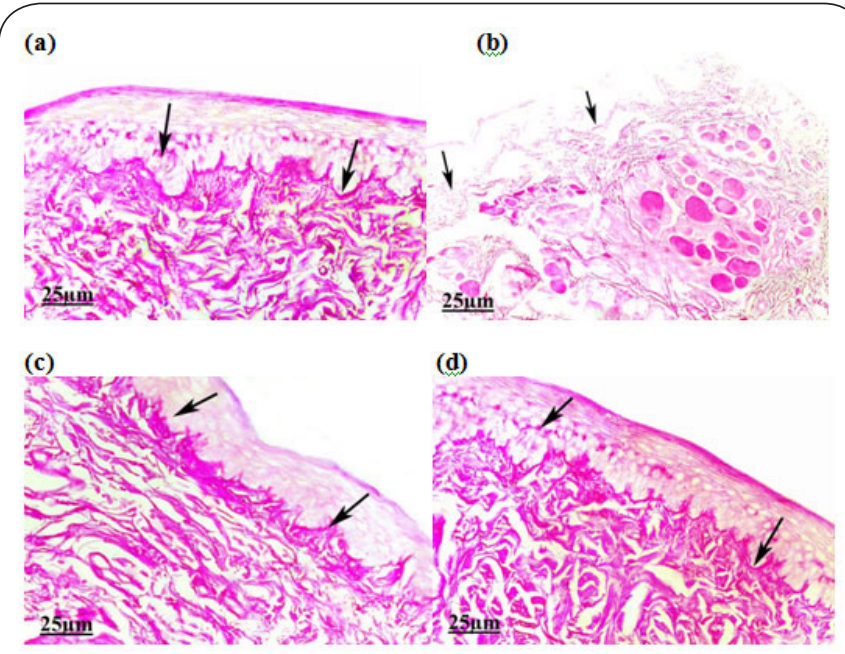

Figure 2. A photomicrograph of buccal mucosa stained with Periodic acid Schiff (PAS).

(a) Buccal mucosa from group I showing intense PAS positive reaction (arrow) [PAS, X400, scale bar $=25 \mu \mathrm{m}$ ]. (b) Buccal mucosa from group II showing weak PAS positive reaction (arrow) [PAS, X400, scale bar $=25 \mu \mathrm{m}$ ]. (c) Buccal mucosa from group III showing intense PAS positive reaction (arrow) [PAS, X400, scale bar $=25 \mu \mathrm{m}]$. (d) Buccal mucosa from group IV showing intense PAS positive reaction (arrow) [PAS, X400, scale bar $=25$ $\mu \mathrm{m}]$.

\section{Immunohistochemical stains}

\section{Caspase immunohistochemical staining}

Positive caspase immunohistochemical staining demonstrated as brownish staining in the cytoplasm of buccal epithelial cells (an index of apoptosis). The control groups showed negative caspase-3 immunostaining (Figure 3a). Group II showed highly expressed caspase-3 immunostaining (Figure 3b), while the reaction was moderate in group III (Figure 3c) and minimal in group IV (Figure 3d).

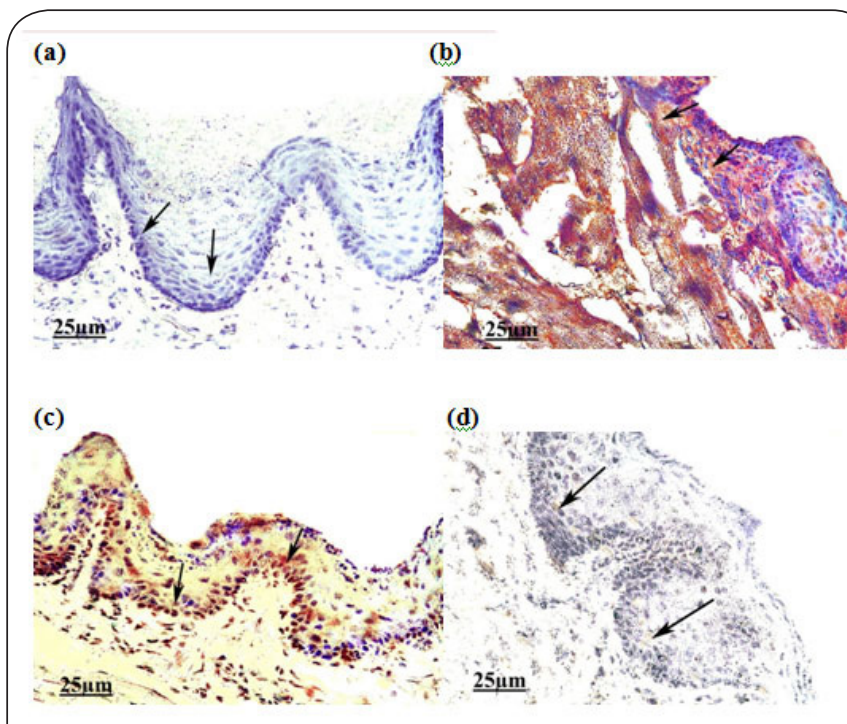

Figure 3. A photomicrograph of buccal mucosa stained with caspase.

(a) Buccal mucosa from group I showing negative caspase-3 immunoreaction in the cytoplasm of buccal epithelial cells (arrow)[Immunostaining for caspase, X400, scale bar $=25 \mu \mathrm{m}$ ]. (b) Buccal mucosa from group II showing highly expressed caspase- 3 immunoreaction in the cytoplasm of buccal epithelial cells (arrow) [Immunostaining for caspase, X400, Scale bar $=25 \mu \mathrm{m}]$. (c) Buccal mucosa of group III showing moderate caspase-3 immunoreaction in the cytoplasm of buccal epithelial cells (arrow) [Immunostaining for caspase, $\mathrm{X} 400$,scale bar $=25 \mu \mathrm{m}]$. (d) Buccal mucosa from group IV showing minimal expressed caspase- 3 immunoreaction in the cytoplasm of buccal epithelial cells (arrow) [Immunostaining for caspase, $\mathrm{X} 400$, scale bar $=25 \mu \mathrm{m}]$.

\section{PCNA immunohistochemical staining}

It demonstrated as brown PCNA positive nuclei among basal cell layers of the buccal epithelium. The control groups showed many brown PCNA positive nuclei (Figure 4a). Group II revealed few brown PCNA positive nuclei (Figure 4b), where group III showed moderate brown PCNA positive nuclei (Figure 4c), but many brown PCNA positive nuclei in group IV (Figure 4d).

\section{Morphometric results}

As shown in Tables 1 and $\mathbf{3}$ and (Histograms 1 and $\mathbf{3}$ ). The mean area percentage of PAS staining and PCNA positive immunostaining were significantly decreased in groups II compared with group I $(\mathrm{P}<0.01)$, but was significantly increased in groups III\&IV compared with group II $(P<0.01)$. As shown in Table 2 and Histogram 2: Mean area percentage 


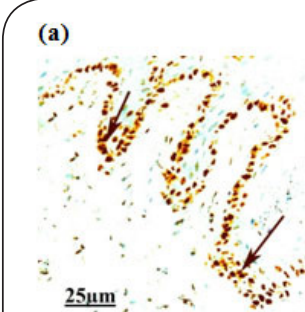

(c)

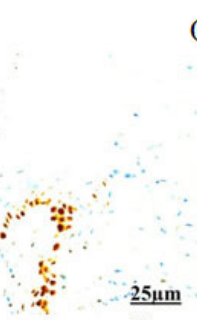

(b)

(d)

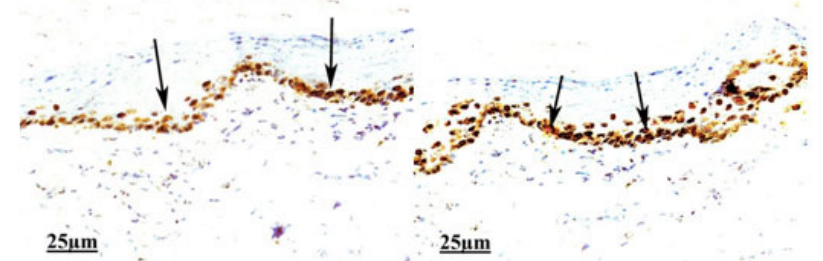

Figure 4. A photomicrograph of buccal mucosa of antiproliferating cell nuclear antigen (PCNA).

(a) Buccal mucosa from group I showing many brown PCNA positive nuclei among basal cell layers of the buccal epithelium (arrow) [Immunostaining for PCNA X400, scale bar $=25 \mu \mathrm{m}$ ]. (b) Buccal mucosa from group II showing few brown PCNA positive nuclei among basal cell layers of the buccal epithelium (arrow) [Immunostaining for PCNA X400, scale bar $=25 \mu \mathrm{m}$ ]. (c) Buccal mucosa from group III showing moderate brown PCNA positive nuclei among basal cell layers of the buccal epithelium (arrow) [Immunostaining for PCNA X400,scale bar $=25 \mu \mathrm{m}$ ]. (d) Buccal mucosa of group IV showing many brown PCNA positive nuclei among basal cell layers of the buccal epithelium (arrow) [Immunostaining for PCNA $\mathrm{X} 400$,scale bar $=25 \mu \mathrm{m}]$.

Table 1. Showing the mean area $\%$ and \pm SD of PAS positive reaction in groups I, II, III and IV with comparison between all groups by Post Hoc Scheffe's test.

\begin{tabular}{lllll}
\hline & Group I & Group II & Group III & Group IV \\
\hline Mean area $\%$ & $25.53 \%$ & $5.96 \%$ & $34.79 \%$ & $37.65 \%$ \\
SD & 1.6149 & 1.2357 & 1.0343 & 0.6899 \\
Significance at & $2,3,4$ & $1,3,4$ & $1,2,4$ & $1,2,3$ \\
P $<0.01$ & & & & \\
\hline
\end{tabular}

1=sig \& group I $2=$ sig \& group II $3=$ sig \& group III $4=$ sig \& group IV

Table 2. Showing the mean area $\%$ and \pm SD of caspase- 3 immunoreactivity in groups I, II, III and IV with comparison between all groups by Post Hoc Scheffe's test.

\begin{tabular}{lllll}
\hline & Group I & Group II & Group III & Group IV \\
\hline Mean area \% & $0.00 \%$ & $16.42 \%$ & $5.40 \%$ & $1.86 \%$ \\
SD & 0 & 1.2861 & 0.4809 & 0.3697 \\
Significance at & $2,3,4$ & $1,3,4$ & $1,2,4$ & $1,2,3$ \\
P $<0.01$ & & & & \\
\hline
\end{tabular}

$1=$ sig \& group I $2=$ sig \& group II $3=$ sig \& group III $4=$ sig \& group IV

of caspase-3 immunostaining was significantly increased in groups II compared with group I $(P<0.01)$, but there was a
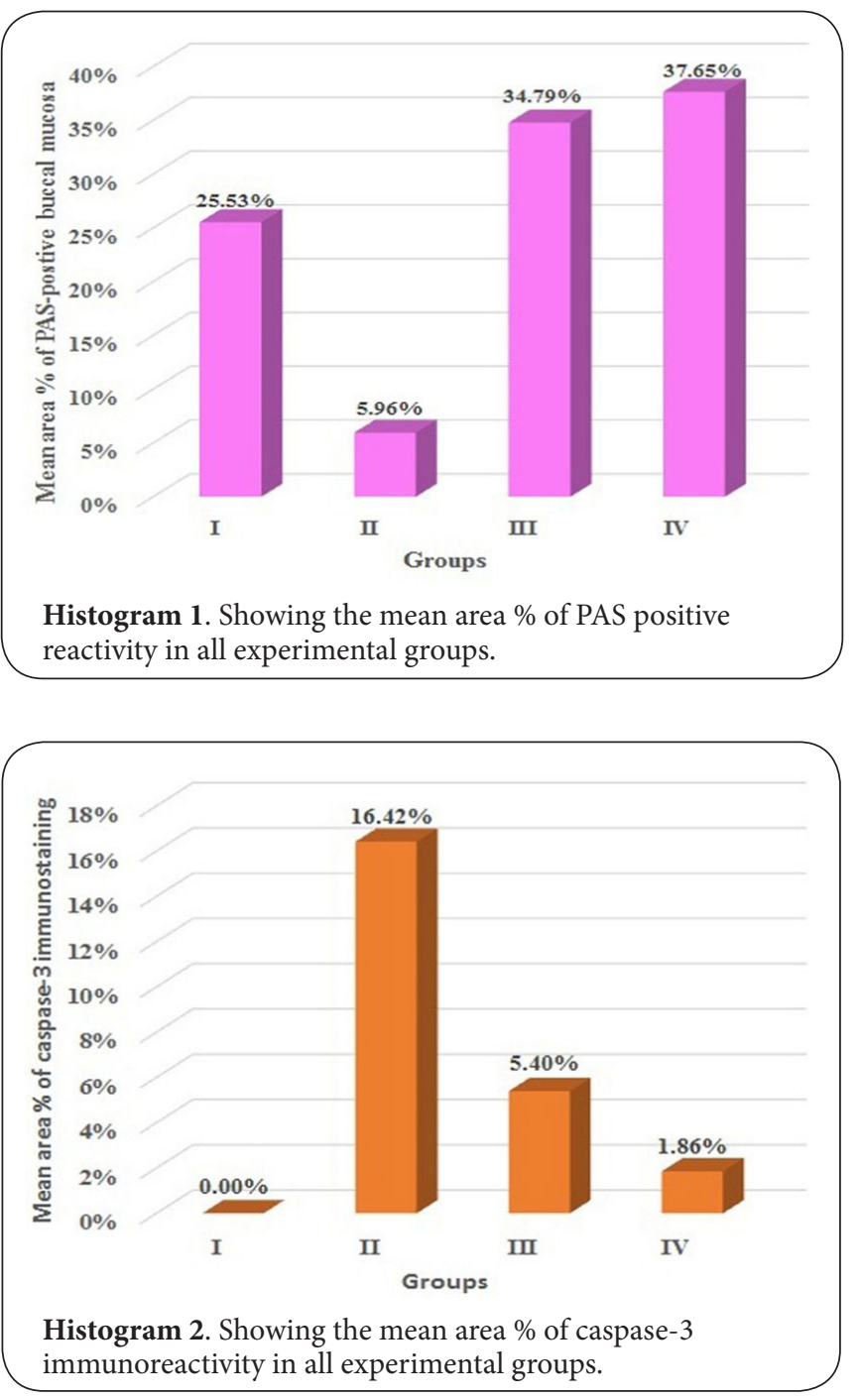

Table 3. Showing the mean area $\%$ and \pm SD of PCNA immunoreactivity in groups I, II, III and IV with comparison between all groups byPost Hoc Scheffe's test.

\begin{tabular}{lllll}
\hline & Group I & Group II & Group III & Group IV \\
\hline Mean area \% & $3.57 \%$ & $0.14 \%$ & $1.78 \%$ & $4.01 \%$ \\
$\mathrm{SD} \pm$ & 0.4417 & 0.0440 & 0.3634 & 0.4624 \\
Significance at & 2,3 & $1,3,4$ & $1,2,4$ & 2,3 \\
$\mathrm{P}<0.01$ & & & & \\
\hline
\end{tabular}

$1=$ sig \& group I $2=$ sig \& group II $3=$ sig \& group III $4=$ sig \& group IV

significant decrease in groups III\& IV compared with group II $(\mathrm{P}<0.01)$.

\section{Discussion}

Oral mucositis is a complex process initiated by injury to cells in the basal epithelium and underlying tissue of oral mucosa and has a frequent painful drawbacks associated 


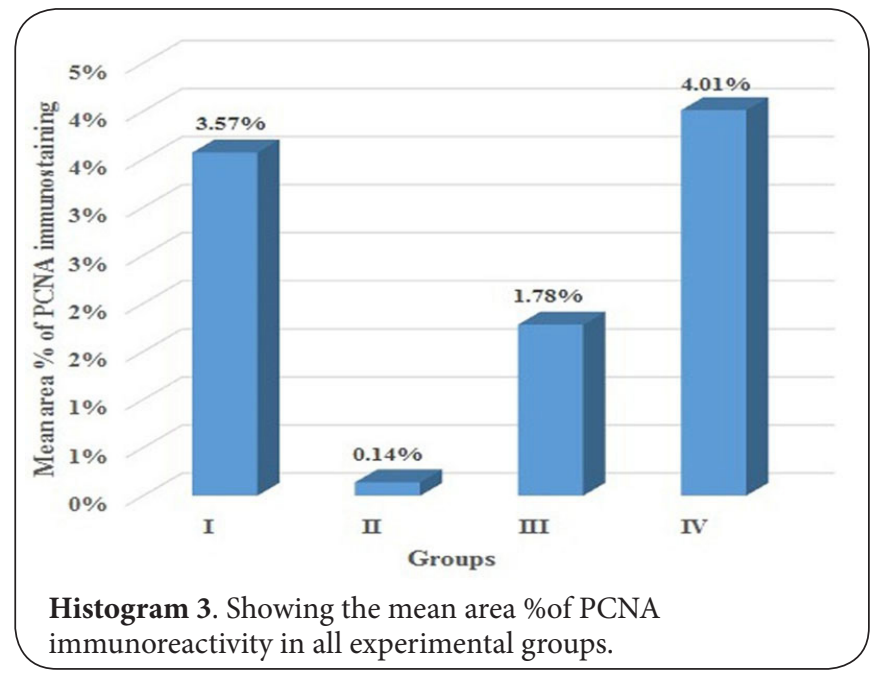

with mucosal barrier injury $[2,7,22]$.

5-Flurouracil administration has been performed as a method to induce oral mucositis in rats and the inception of lesions usually occurs within five to seven days of their administration, thus the mouth becomes ready for entrance of viruses, bacteria and fungi. Hence, the oral mucosa becomes susceptible to an augmented danger of infection

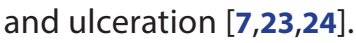

The examination of buccal mucosa sections of group II revealed various histological changes as apparent diminish in the thickness of the epithelium with separation of keratin and flattening of rete ridges. Some epithelial cells had cytoplasmic perinuclear vacuolization, while others had various nuclear changes as karyohexiss, pyknosis or karyolysis and hemorrhage. There were areas of degeneration and intense subepithelial mononuclear infiltration in lamina propria. Moreover, there was a significant reduction in PAS positive reaction in reactivity in buccal epithelial cells and basal lamina. These results were in agreement with some scientists $[1,3,18,25,26]$ who suggested that 5 -Flurouracil was potent chemotherapeutical agent inducing oral mucosal destruction which was an anatomical barrier.

Some investigators $[4,5,7]$ clarified that 5-Flurouracil induced oral mucositis correlated with increased expression of several cytokines as tumor necrosis factor- $a$ (TNF- $a$ ) and interleukin-1(IL-1), which trigger an inflammatory response. Furthermore, the defect of the oral mucosal barriers might cause bacterial invasion. These bacteria were also chemotactic factor for mononuclear cells leading to mucositis and finally mucosal ulceration.

Group II of our research revealed also a significantly rise expression of caspase-3 reaction in the cytoplasm of buccal epithelial cells which was an index of apoptosis. Moreover, there was a significant reduction in expression of PCNA immunostaining in the basal and prickle cell layers of buccal epithelium, which was an index of proliferation.

Apoptosis is an important sequel of mucositis induced by chemotherapeutic agents as 5 -FU. Caspase- 3 is the major downstream effector in apoptosis. Some researchers reported that 5 -Flurouracil induces DNA damage and the production of reactive oxygen species, deteriorates the metabolism in progenitor cells and causes inhibition of mitosis and rises of apoptosis $[\mathbf{2 , 3}, \mathbf{6}, \mathbf{2 7}]$. Other scientists $[\mathbf{5 , 2 3 , 2 4 ]}$ found that the toxicity of chemotherapeutic agents as 5 -FU decreases proliferation of cells of mucosa, also impairment of their cellular renewal or regeneration and thus lead to significant decrease of PCNA immunostaining expression of the mucosal cells.

Previous researchers $[\mathbf{7 , 1 8 , 2 8}]$ suggested that the most possible mechanism of action of 5-Flurouracil induced oral mucositis facilitated through complex biological process as liberating of several inflammatory cytokines, development of oxidative stress and propagation of reactive oxygen species (ROS) and increasing the expression of nuclear factor-kappa B. In addition, retardation of cell proliferation, suppression the synthesis of essential components of deoxyribonucleic acid (DNA) and ribonucleic acid (RNA) were other submitted mechanisms.

Group III of the present research revealed keratin layer and apparently degree of re-epithelialization with restoring of rete ridges. There were subepithelial mononuclear infiltration, cytoplasmic perinuclear vacuolization and a significant rise in the PAS positive reaction in buccal mucosa. Furthermore a significant reduction in caspase immunoreactions in the cytoplasm of buccal epithelial cells, while a significant increase of expression PCNA immunostaining of these cells as compared with group II. These results were identity and confirming the findings of some investigators [9], who reported that glucosamine has accelerated the process of wound healing, re-epithelization and the tissue regeneration rate. Preservation of the histological structures with glucosamine is explained by some investigators $[\mathbf{8 , 1 0 , 2 9 ]}$ stated that glucosamine possesses an immune-modulatory influence by decreasing inflammation, neutrophil recruitment through the down regulation of inflammatory factors as TNF-a, IL-1, and IL-6. Moreover, GIcN increases the antioxidant activity owing to its constituents such as flavonoids, phenols, Tannis (Phenolic compounds) and Triterpenoids. Also, it prevents DNA damage and reduces apoptosis and accelerates the cellular growth and proliferation in vitro [10,29-31].

Group IV of this study revealed restoration of normal stratified squamous epithelium, keratin layer and also rete ridges with well-organized lamina propria and a significant increase in the PAS positive reaction in buccal mucosa. Furthermore a significant decrease of expression caspase reaction in the cytoplasm of buccal epithelial cells, while a significant increase of expression PCNA immunostaining of these cells as compared with group II. These results were an identity with previous researchers [12,17,32-34], who stated that PRP promotes healing in a different form of lesions because it has many important bioactive proteins hastens the endothelial, mesenchymal, epithelial and epidermal 
regeneration, decreases inflammation and speeds wound healing in normal tissues as well as healing of impaired wounds.

Intralesional injection of PRP was proceeded as it offers a selective spreading in the targeted parts of the wound that require more aid in the healing process and therefore a reduction in the required volume of PRP [35]. Both recent experimental and clinical studies $[11,17]$ have revealed that intralesional injection of PRP in wound healing and muscle injuries lead to better regeneration, increasing neovascularization, reducing fibrosis and scarring. Previous related studies [35-37] had proved that the therapeutic value of PRP in mainly due to high platelet count. Platelets are stimulated by exposure to injured tissues leading to commencement of the coagulation process, which are the onset of the platelets role in healing. Once activated, they liberate their granular contents towards the wound areas. These contents are of specific interest in healing process as they contain many anabolic growth factors such as plateletderived growth factor, vascular endothelial growth factor and transforming growth factor. These factors stimulates cell proliferation, promote chemotaxis, differentiation and metabolism regulation, also mediate mitogenesis and the antiapoptotic effect through many receptors. Other authors $[14,17]$ revealed that PRP products containing white blood cells, which capable to inhibit the growth of some bacteria and improve healing in soft tissue injuries associated with infection through release of bactericidal factors.

\section{Conclusion}

GlcN and PRP provide a promising treatment for oral mucositis associated with chemotherapy. PRP remedy is simple and the most efficient mean as it exhibits more rapid epithelial differentiation and wound healing.

\section{Competing interests}

The authors declare that they have no competing interests.

Authors' contributions

\begin{tabular}{|l|c|c|c|}
\hline Authors' contributions & AEM & NEE & AMEM \\
\hline Research concept and design & $\checkmark$ & $\checkmark$ & $\checkmark$ \\
\hline Collection and/or assembly of data & $\checkmark$ & $\checkmark$ & $\checkmark$ \\
\hline Data analysis and interpretation & $\checkmark$ & $\checkmark$ & $\checkmark$ \\
\hline Writing the article & -- & $\checkmark$ & $\checkmark$ \\
\hline Critical revision of the article & -- & $\checkmark$ & $\checkmark$ \\
\hline Final approval of article & $\checkmark$ & $\checkmark$ & $\checkmark$ \\
\hline Statistical analysis & $\checkmark$ & -- & -- \\
\hline
\end{tabular}

Publication history

EIC: Gaetano Giuseppe Magro, University of Catania, Italy. Received: 26-Sep-2017 Final Revised: 18-Oct-2017 Accepted: 24-Oct-2017 Published: 05-Nov-2017

\section{References}

1. Mahdi AK, Al-Falahi NH and Nahi HH. Effects of chitosan and hyaluronic acid in healing of chemically induced oral ulcer in rabbits. Kufa Journal for Veterinary Medical Sciences. 2016; 7:138-151.

2. Ahmed KM, Talabani $\mathrm{N}$ and Altaei T. Olive leaf extract as a new topical management for oral mucositis following chemotherapy: a microbiological examination, experimental animal study and clinical trial. Pharmaceut. Anal. Acta. 2013; 4:1-18. | Article

3. Al-Refai AS. Immunohistochemical study of the effect of chamomile extract on 5-fluorouracil induced intestinal mucositis in albino rats. J. Clin. Celllmmunol. 2014; 5:1-10.

4. Alvarino-Martin $C$ and Sarrion-Perez MG. Prevention and treatment of oral mucositis in patients receiving chemotherapy. J Clin Exp Dent. 2014; 6:e74-80. | Article | PubMed Abstract | PubMed FullText

5. Al-Refai AS. Chemoprotective effect of ascorbic acid on cyclophosphomide induced oral toxicity. Zanco J. Med. Sci. 2017; 21:1540-1551.

6. Koizumi R, Azuma K, Izawa H, Morimoto M, Ochi K, Tsuka T, Imagawa T, Osaki T, Ito N, Okamoto Y, Saimoto H and Ifuku S. Oral Administration of Surface-Deacetylated Chitin Nanofibers and Chitosan Inhibit 5-Fluorouracil-Induced Intestinal Mucositis in Mice. Int J Mol Sci. 2017; 18. | Article | PubMed Abstract | PubMed FullText

7. Watanabe S, Suemaru K, Takechi K, Kaji H, Imai K and Araki H. Oral mucosal adhesive films containing royal jelly accelerate recovery from 5-fluorouracil-induced oral mucositis. J Pharmacol Sci. 2013; 121:110-8. | Article | PubMed

8. Arafa NM, Hamuda HM, Melek ST and Darwish SK. The effectiveness of Echinacea extract or composite glucosamine, chondroitin and methyl sulfonyl methane supplements on acute and chronic rheumatoid arthritis rat model. Toxicol Ind Health. 2013; 29:187-201. | Article | PubMed

9. Mostafa MHA. Histological study on the effect of topical application of glucosamine on wound healing in rats. The Egyptian Journal of Histology. 2014; 37:640-654. I Article

10. Chen YJ, Huang YS, Chen JT, Chen YH, Tai MC, Chen CL and Liang CM. Protective effects of glucosamine on oxidative-stress and ischemia/ reperfusion-induced retinal injury. Invest Ophthalmol Vis Sci. 2015; 56:1506-16. | Article | PubMed

11. Quarteiro ML, Tognini JR, de Oliveira EL and Silveira I. The effect of platelet-rich plasma on the repair of muscle injuries in rats. Rev Bras Ortop. 2015; 50:586-95. | Article | PubMed Abstract | PubMed FullText

12. Atalay Y, Bozkurt MF, Gonul Y, Cakmak O, Agacayak KS, Kose I, Hazman $\mathrm{O}$, Keles $\mathrm{H}$, Turamanlar $\mathrm{O}$ and Eroglu $\mathrm{M}$. The effects of amlodipine and platelet rich plasma on bone healing in rats. Drug Des Devel Ther. 2015; 9:1973-81. | Article | PubMed Abstract | PubMed FullText

13. Girgin M, Binnetoglu K, Duman K, Kanat BH, Cetinkaya Z, Ayten R, Ilhan YS, Ilhan N, Seker I and Timurkaan N. Effects of platelet rich plasma on fascial healing in rats with fecal peritonitis. Acta Cir Bras. 2016; 31:3149. | Article | PubMed

14. Martin-Sole O, Rodo J, Garcia-Aparicio L, Blanch J, Cusi V and Albert A. Effects of Platelet-Rich Plasma (PRP) on a Model of Renal IschemiaReperfusion in Rats. PLoS One. 2016; 11:e0160703. | Article | PubMed Abstract | PubMed FullText

15. Al-Asmari AK, Khan AQ, Al-Qasim AM and Al-Yousef Y. Ascorbic acid attenuates antineoplastic drug 5-fluorouracil induced gastrointestinal toxicity in rats by modulating the expression of inflammatory mediators. Toxicol Rep. 2015; 2:908-916. | Article | PubMed Abstract | PubMed FullText

16. Sebe M, Tsutsumi R, YamaguchiS, Horikawa Y, HaradaN and Oyama T. The synergystic effects of omega-3 fatty acids against 5-fluorouracil-induced mucosal impairment in mice. BMC Nutrition. 2016, 2:1-10. | Article

17. Mohammadi R, Mehrtash M, Hassani N and Hassanpour A. Effect of 
Mansy et al. Journal of Histology \& Histopathology 2017,

Platelet Rich Plasma Combined with Chitosan Biodegradable Film on Full-Thickness Wound Healing in Rat Model. Bull Emerg Trauma. 2016; 4:29-37. | PubMed Abstract | PubMed FullText

18. Chang $\mathrm{CT}$, Hsiang $\mathrm{CY}, \mathrm{Ho} \mathrm{TY}$, Wu CZ, Hong $\mathrm{HH}$ and Huang YF. Comprehensive Assessment of Host Responses to 5-FluorouracilInduced Oral Mucositis through Transcriptomic Analysis. PLoS One. 2015; 10:e0135102. | Article | PubMed Abstract | PubMed FullText

19. Elsaadany B, El Kholy S, El Rouby D, Rashed L and Shouman T. Effect of Transplantation of Bone Marrow Derived Mesenchymal Stem Cells and Platelets Rich Plasma on Experimental Model of Radiation Induced Oral Mucosal Injury in Albino Rats. Int J Dent. 2017; 2017:8634540. | Article | PubMed Abstract | PubMed FullText

20. Bancroft JD and Layton C. The hematoxylin and eosin, connective mesenchymal tissues with their stains In. Suvarna SK, Layton C and Bancroft JD, editors. Bancroft's Theory and practice of histological techniques. 7th edition. Churchill Livingstone: Philadelphia. 2013; 173212\&215-238.

21. Jackson $P$ and Blythe D. Immunohistochemical techniques [chapter 8]. In: Suvarna SK, Layton C, Bancroft JD, editors. Theory and practice of histological techniques. 7th ed. Philadelphia: Churchill Livingstone of Elsevier. 2013; 381-434.

22. Freitas AP, Bitencourt FS, Brito GA, de Alencar NM, Ribeiro RA, LimaJunior RC, Ramos MV and Vale ML. Protein fraction of Calotropis procera latex protects against 5-fluorouracil-induced oral mucositis associated with downregulation of pivotal pro-inflammatory mediators. Naunyn Schmiedebergs Arch Pharmacol. 2012; 385:981-90. | Article | PubMed

23. Lotfy AO and Zayed M. Immunohistochemical study of the effect of Nigella Sativa L extract on chemotherapy induced oral mucositis in albino rats. Cairo Dental Journal. 2009; 25:159:166.

24. Won JH, Ji JE, Ahn KH, Kim SK, Choi JM, Ha HC, Kim HM, Yun CK, Han K and Kim DK. Effect of rice cell-derived human granulocyte-macrophage colony-stimulating factor on 5-fluorouracil-induced mucositis in hamsters. Biol Pharm Bull. 2013; 36:425-31. | Article | PubMed

25. El-Bermawy MI. Light and scanning electron microscopic study of 5-fluorouracil-induced mucosal injury in the gastric fundus and the possible protective role of omeprazole in adult male albino rats. The Egyptian Journal of Histology. 2015; 38:415-426. | Article

26. Patel A, Biswas S, Shoja MH, Ramalingayya GV and Nandakumar K. Protective effects of aqueous extract of Solanum nigrum Linn. leaves in rat models of oral mucositis. ScientificWorldJournal. 2014; 2014:345939. | Article | PubMed Abstract | PubMed FullText

27. Chang CT, Ho TY, Lin H, Liang JA, Huang HC, Li CC, Lo HY, Wu SL, Huang YF and Hsiang CY. 5-Fluorouracil induced intestinal mucositis via nuclear factor-kappaB activation by transcriptomic analysis and in vivo bioluminescence imaging. PLoS One. 2012; 7:e31808. | Article | PubMed Abstract | PubMed FullText

28. Generoso Sde V, Rodrigues NM, Trindade LM, Paiva NC, Cardoso VN, Carneiro CM, Ferreira AV, Faria AM and Maioli TU. Dietary supplementation with omega-3 fatty acid attenuates 5 -fluorouracil induced mucositis in mice. Lipids Health Dis. 2015; 14:54. | Article | PubMed Abstract | PubMed FullText

29. Haleagrahara N, Tudawe D, Chakravarthi S and Kutty Radhakrishnan A. Amelioration of collagen-induced arthritis in female dark agouti rats by glucosamine treatment. ISRN Pharmacol. 2013; 2013:562905. | Article | PubMed Abstract I PubMed FullText

30. Matsunaga T, Yanagiguchi K, Yamada S, Ohara N, Ikeda T and Hayashi $Y$. Chitosan monomer promotes tissue regeneration on dental pulp wounds. J Biomed Mater Res A. 2006; 76:711-20. | Article | PubMed

31. Nagy MA and Bastawy MA. Reno protective effects of Egyptian herbal formula during experimental diabetes 2012; 1:1-7. I Pdf

32. Allahverdi A, Sharifi D, Takhtfooladi MA, Hesaraki S, Khansari M and Dorbeh SS. Evaluation of low-level laser therapy, platelet-rich plasma, and their combination on the healing of Achilles tendon in rabbits.
Lasers Med Sci. 2015; 30:1305-13. | Article | PubMed

33. Sarkarat F, Kalantar Motamedi MH, Jahanbani J, Sepehri D, Kahali R and Nematollahi Z. Platelet-Rich Plasma in Treatment of Zoledronic AcidInduced Bisphosphonate-related Osteonecrosis of the Jaws. Trauma Mon. 2014; 19:e17196. | Article | PubMed Abstract | PubMed FullText

34. Tavakolinejad S, Alamdari DA, Khajehahmadi S, Khordad E and Ebrahimzadeh $\mathrm{A}$. Cleft palate reconstruction by palate- rich plasma and stem cell injection: Histological evidence. J. Cell Anim. Biol. 2014; 8:114-123.

35. Jee CH, Eom NY, Jang HM, Jung HW, Choi ES, Won JH, Hong IH, Kang $B T$, Jeong DW and Jung DI. Effect of autologous platelet-rich plasma application on cutaneous wound healing in dogs. J Vet Sci. 2016; 17:7987. | Article | PubMed Abstract | PubMed FullText

36. Kucuk L, Gunay H, Erbas O, Kucuk U, Atamaz F and Coskunol E. Effects of platelet-rich plasma on nerve regeneration in a rat model. Acta Orthop Traumatol Turc. 2014; 48:449-54. | Article | PubMed

37. Donmez MI, Inci K, Zeybek ND, Dogan HS and Ergen A. The Early Histological Effects of Intravesical Instillation of Platelet-Rich Plasma in Cystitis Models. Int Neurourol J. 2016; 20:188-196. | Article | PubMed Abstract | PubMed FullText

\section{Citation:}

Mansy AE, El-Azab NE-E and El-Mahalaway AM. Histological and immunohistochemical study of the potential healing effects of glucosamine and platelets rich plasma on experimentally induced oral mucositis in adult male rats.

J Histol Histopathol. 2017; 4:12. http://dx.doi.org/10.7243/2055-091X-4-12 